\title{
Metabolic syndrome in children
}

\section{Alan R. Sinaiko*}

Metabolic syndrome (consisting of increased waist circumference, hypertension, hypertriglyceridemia, low highdensity lipoprotein cholesterol [HDL-C], and hyperglycemia) became a medical diagnosis in adults in the late 1980s after publication of the concept that these cardiovascular (CV) risk factors may be linked together through a relation with insulin resistance. ${ }^{1}$ The syndrome later became formally defined as the presence of any three of the above five components, ${ }^{2}$ and it is widely accepted as an important predictor of $\mathrm{CV}$ disease and type 2 diabetes.

It is no secret that obesity has become a major universal health issue in children, that it is associated with significant metabolic dysfunction, and that it tracks into adulthood. Thus, it is not surprising that attempts have been made to develop a metabolic syndrome for children patterned on the adult syndrome. While the adult diagnosis is based on well-defined definitions for the five components comprising the syndrome, similar definitions are not available in children. As a consequence, arbitrary cutoff points, adapted from childhood standards, have been substituted. Using these criteria, it was estimated that the prevalence of the metabolic syndrome in adolescents was approximately $4 \%$, with an increase to $29 \%$ in overweight adolescents. ${ }^{3}$ However, the use of arbitrary definitions has led to controversy in pediatrics. The result is clearly shown in the paper by Costa et al. ${ }^{4}$ published this month in the Journal, comparing three prevalence studies, each with its own separate independent definitions for diagnosing the metabolic syndrome. It is not clear why the different definitions were chosen, but the outcome is clear, i.e., three different definitions lead to three substantially different levels of prevalence for the childhood metabolic syndrome. It is understandable, as Costa et al. conclude, "disagreements regarding the prevalence of the disease in the pediatric population will be frequent".
There is general agreement that the risk factors comprising the metabolic syndrome tend to cluster together. However, there are differences between adults and children. A variety of combinations of all five components may be found in adults with the syndrome, but in children obesity predominates, associated in most cases with elevated triglycerides and low HDL-C. Despite the high correlation with body mass index (BMI), hypertension is infrequent; and fasting hyperglycemia, common in adult obesity, is least common. Although fasting glucose levels may be higher in obese than non-obese children, the levels are usually within the normal range, requiring an oral glucose tolerance test to diagnose disordered glucose metabolism. ${ }^{5}$ The lower frequency of hypertension and hyperglycemia may explain, in part, the lower prevalence of the syndrome in children than adults. As seen in Costa et al.'s Table 4, prevalence can be easily influenced by altering the definition of any of the five components, noted in this case by the major effect of lowering the threshold for HDL-C and waist circumference by de Ferranti.

Emphasis on elevated CV risk factors in children is logical for pediatricians, who have always been at the forefront of preventive medicine. However, it is important to recognize that a focus on the metabolic syndrome rather than the individual risk factors may detract from the most effective approach to preventive care or therapy. First, the metabolic syndrome tracks poorly during childhood, 6,7 from childhood to young adulthood, ${ }^{8}$ and to a greater degree in children in the higher risk categories. ${ }^{9}$ As a consequence, major advisory bodies have raised questions about its usefulness in children. ${ }^{10}$ The lack of tracking may be explained by longitudinal studies showing significant changes in levels of blood pressure, triglycerides and $\mathrm{HDL}-\mathrm{C}$ during the transition from childhood to young adulthood. ${ }^{11}$ These changes and the resultant variability in levels are likely to have a major

* Professor, Department of Pediatrics, Division of Pediatric Nephrology, Medical School, and Division of Epidemiology, School of Public Health, University of Minnesota, Minneapolis, Minnesota, USA.

No conflicts of interest declared concerning the publication of this editorial.

Suggested citation: Sinaiko AR. Metabolic syndrome in children. J Pediatr (Rio J). 2012;88(4):286-8.

http://dx.doi.org/10.2223/JPED.2214 
impact on diagnosis of the metabolic syndrome, which depends on rigid dichotomization of risk factor levels. Second, obesity is the strongest determinant of elevated $\mathrm{CV}$ risk. Although diagnosis of the metabolic syndrome requires abnormal levels of three of the five components, as shown in the study by Costa, a significant percentage of obese children have adverse levels in only one or two, as opposed to three. Other studies in children have shown that obesity is the single factor routinely associated, either cross-sectionally ${ }^{12}$ or longitudinally ${ }^{8}$ with clustering of the risk factors, and it is equal to the metabolic syndrome in predicting adult risk. ${ }^{13}$ Moreover, many studies have reported the exceptionally strong tracking effect of obesity from childhood to adulthood. It appears that placing greater emphasis on early recognition of obesity and elevated individual risk factors, rather than searching for a syndrome of factors, would be more productive in pediatric care.

Despite the failure of the metabolic syndrome to track significantly during childhood or from childhood to adulthood, there is an association between clustering of elevated risk factors in childhood with risk factor levels later in life. Our studies have shown that while only $16 \%$ of children with the metabolic syndrome at mean age 13 had the syndrome at mean age 22 , they had significantly higher levels of BMI, waist circumference, percent body fat, and triglycerides and significantly lower levels of HDL-C, compared to individuals without the syndrome at age 13.8 In an attempt to design a more reliable method than the metabolic syndrome for evaluating degrees of $\mathrm{CV}$ risk in children, we developed a metabolic factor cluster score by taking the average of the standardized deviates of the five metabolic syndrome criteria. The results were striking, with the cluster score at age 22 approximately eight times higher in the individuals with metabolic syndrome at age 13 than the non-metabolic syndrome group. In addition, there was a strong tracking effect for the cluster score $(r=0.51, p<0.0001)$, indicating that relative rank of the cluster score at age 13 predicted its rank at age 22 . These findings are consistent with the risk factor components of the metabolic syndrome being continuous variables with graded risk, rather than having threshold levels of risk that are compatible with dichotomization into normal and abnormal values.

Substituting homeostatic model assessment (HOMA) for fasting plasma glucose significantly increased the percentage of children with metabolic syndrome in each of the three prevalence studies. The HOMA measurement was developed in an attempt to provide a less burdensome surrogate measure of insulin resistance than the more involved direct measures, such as the euglycemic, hyperinsulinemic clamp. However, despite the combination of fasting glucose and insulin, HOMA is not an improvement over fasting insulin alone, with a correlation of $r=0.99$ in children ${ }^{14}$ and an equally high correlation in adults. Moreover, it is a poor estimate of insulin resistance in children, particularly in thin children. ${ }^{14}$ It is not surprising that including HOMA instead of fasting glucose in the metabolic syndrome would significantly increase prevalence. This is most likely related to the confounding effect of fatness on insulin levels, as evidenced by the high correlation between fasting insulin and BMI in children ${ }^{15}$ and the influence of obesity on insulin hypersecretion independent from obesity-related insulin resistance. 16

The relation between insulin resistance and the metabolic syndrome (or clustering of CV risk factors) has long been attractive as an etiologic unifying concept. ${ }^{17}$ However, despite the significant relation between BMI and insulin resistance, studies in adults and children have shown that not all obese individuals are insulin resistant. Using data from a cohort of obese adults, the highest levels of insulin resistance were associated with the highest levels of blood pressure, plasma glucose and lipids. ${ }^{18}$ Our studies have shown 1) in a cohort of 30015 year olds significantly higher levels of CV risk factors are found in heavy-insulin resistant adolescents than heavy-insulin sensitive adolescents ${ }^{19}$; and 2) levels of insulin resistance at age 13 predict levels of blood pressure, triglycerides and a cluster score at age 19. 20 Thus, it appears that insulin resistance has a relevant, but undefined, role in early CV risk development.

The paper by Costa et al. points out the complex nature of the metabolic syndrome. How then, should CV risk be addressed in children? Based on available information, the following can be concluded: 1) thin children, without strong genetic history, rarely have elevated CV risk factors; 2) elevated CV risk has a significant relation to insulin resistance, but currently there are no simple and effective methods for measuring it; 3) obese children should be screened for elevated CV risk factors, with an emphasis on identifying abnormal factors as opposed to relying on the metabolic syndrome to determine degree of risk.

\section{References}

1. Reaven GM. Banting lecture 1988. Role of insulin resistance in human disease. Diabetes. 1988;37:1595-607.

2. Grundy SM, Brewer HB Jr, Cleeman JI, Smith SC Jr, Lenfant C; American Heart Association, et al. Definition of metabolic syndrome: Report of the National Heart, Lung, and Blood Institute/ American Heart Association conference on scientific issues related to definition. Circulation. 2004;109:433-8.

3. Cook S, Weitzman M, Auinger P, Nguyen M, Dietz WH. Prevalence of a metabolic syndrome phenotype in adolescents: findings from the third National Health and Nutrition Examination Survey, 19881994. Arch Pediatr Adolesc Med. 2003;157:821-7.

4. Costa RF, Santos NS, Goldraich NP, Barski TF, de Andrade KS, Kruel LF. Metabolic syndrome in obese adolescents: a comparison of three different diagnostic criteria. J Pediatr (Rio J). 2012;88:303-9.

5. Sinha R, Fisch G, Teague B, Tamborlane WV, Banyas B, Allen $\mathrm{K}$, et al. Prevalence of impaired glucose tolerance among children and adolescents with marked obesity. N Engl J Med. 2002;346:802-10. 
6. Goodman E, Daniels SR, Meigs JB, Dolan LM. Instability in the diagnosis of metabolic syndrome in adolescents. Circulation. 2007;115:2316-22.

7. Gustafson JK, Yanoff LB, Easter BD, Brady SM, Keil MF, Roberts $M D$, et al. The stability of metabolic syndrome in children and adolescents. J Clin Endocrinol Metab. 2009;94:4828-34.

8. Kelly AS, Steinberger J, Jacobs DR, Hong CP, Moran A, Sinaiko AR. Predicting cardiovascular risk in young adulthood from the metabolic syndrome, its component risk factors, and a cluster score in childhood. Int J Pediatr Obes. 2011;6:e283-9.

9. Li C, Ford ES, Huang TT, Sun SS, Goodman E. Patterns of change in cardiometabolic risk factors associated with the metabolic syndrome among children and adolescents: the Fels Longitudinal Study. J Pediatr. 2009;155:S5.e9-16.

10. Steinberger J, Daniels SR, Eckel RH, Hayman L, Lustig RH, McCrindle B, et al. Progress and challenges in metabolic syndrome in children and adolescents: a scientific statement from the American Heart Association Atherosclerosis, Hypertension, and Obesity in the Young Committee of the Council on Cardiovascular Disease in the Young; Council on Cardiovascular Nursing; and Council on Nutrition, Physical Activity, and Metabolism. Circulation. 2009; 119:628-47.

11. Moran A, Jacobs DR Jr, Steinberger J, Steffen LM, Pankow JS, Hong $\mathrm{CP}$, et al. Changes in insulin resistance and cardiovascular risk during adolescence: establishment of differential risk in males and females. Circulation. 2008;117:2361-8.

12. Goodman E, Dolan LM, Morrison JA, Daniels SR. Factor analysis of clustered cardiovascular risks in adolescence: obesity is the predominant correlate of risk among youth. Circulation. 2005; 111:1970-7.

13. Magnussen CG, Koskinen J, Chen W, Thomson R, Schmidt MD, Srinivasan $\mathrm{SR}$, et al. Pediatric metabolic syndrome predicts adulthood metabolic syndrome, subclinical atherosclerosis, and type 2 diabetes mellitus but is no better than body mass index alone: the Bogalusa Heart Study and the Cardiovascular Risk in Young Finns Study. Circulation. 2010;122:1604-11.
14. Schwartz B, Jacobs DR Jr, Moran A, Steinberger J, Hong CP, Sinaiko AR. Measurement of insulin sensitivity in children: comparison between the euglycemic-hyperinsulinemic clamp and surrogate measures. Diabetes Care. 2008;31:783-8.

15. Weiss R, Dziura J, Burgert TS, Tamborlane WV, Taksali SE, Yeckel $\mathrm{CW}$, et al. Obesity and the metabolic syndrome in children and adolescents. N Engl J Med. 2004;350:2362-74.

16. Ferrannini $E$, Natali A, Bell $P$, Cavallo-Perin $P$, Lalic N, Mingrone $G$. Insulin resistance and hypersecretion in obesity. European Group for the Study of Insulin Resistance (EGIR). J Clin Invest. 1997; 100:1166-73.

17. Ferrannini E. Is insulin resistance the cause of the metabolic syndrome? Ann Med. 2006;38:42-51.

18. McLaughlin T, Abbasi F, Lamendola C, Reaven G. Heterogeneity in the prevalence of risk factors for cardiovascular disease and type 2 diabetes mellitus in obese individuals: effect of differences in insulin sensitivity. Arch Intern Med. 2007;167:642-8.

19. Sinaiko AR, Steinberger J, Moran A, Prineas RJ, Vessby B, Basu $S$, et al. Relation of body mass index and insulin resistance to cardiovascular risk factors, inflammatory factors, and oxidative stress during adolescence. Circulation. 2005;111:1985-91.

20. Sinaiko AR, Steinberger J, Moran A, Hong CP, Prineas RJ, Jacobs DR Jr. Influence of insulin resistance and body mass index at age 13 on systolic blood pressure, triglycerides, and high-density lipoprotein cholesterol at age 19. Hypertension. 2006;48:730-6.

\section{Correspondence:}

Alan R. Sinaiko

Department of Pediatrics, University of Minnesota,

Amplatz Children's Hospital

2450 Riverside Avenue, East Building

MB689, MN 55454 - Minneapolis, MN - USA

Tel.: +1 (612) 625.8483

Fax: +1 (612) 626.2791

E-mail: sinai001@umn.edu 